Reproductive Success after

\title{
Self-pollination and Cross-pollination of Olive Cultivars in Croatia
}

\author{
Gabriela Vuletin Selak ${ }^{1}$, Slavko Perica, Smiljana Goreta Ban, \\ and Mira Radunic \\ Department of Plant Sciences, Institute for Adriatic Crops, Split 21 000, \\ Croatia
}

\author{
Milan Poljak \\ Department of Plant Nutrition, University of Zagreb, Faculty of Agriculture, \\ Zagreb 10 000, Croatia
}

Additional index words. Olea europaea, flowering period, cross-compatibility, selfincompatibility, self-incompatibility index

\begin{abstract}
Olive orchard productivity largely depends on the choice of planted cultivars and their pollination needs. Orchard designs in Croatia are changing because a number of valuable foreign olive cultivars, mostly Italian, have been introduced in this region in the last 30 years. The compatibility relationships of introduced cultivars with autochthonous cultivars are unknown. With the objective of studying reproductive behavior of the most important Croatian cultivars (Drobnica, Lastovka, Levantinka, and Oblica) and their cross-pollination to recently introduced Italian cultivars Leccino and Pendolino, initial and final fruit set in self-pollination versus cross-pollination and free pollination were compared during three flowering seasons. Experiments were conducted in three different orchards (Kastela, Mravince, and Brac) to identify the effect of the environment on reproductive behavior of olive cultivars. The differences of fruit set in five olive cultivars after tested pollination treatments appeared at the time of initial fruit set. Increased final fruit set under cross-pollinations was observed when compared with self-pollination for all olive cultivars in all experimental orchards. In the Mravince orchard, a positive response to cross-pollination was consistent, and fruit set increased under cross-pollination in all cultivars and years with the exception of 'Levantinka' in which no significant differences were noticed between self-pollination treatment and cross-pollination treatments in 2005 . Variable self-fertility behavior from season to season was found for tested cultivars. A self-incompatibility index (ISI) higher than 0.1 was recorded for 'Levantinka' in all experimental years and, therefore, classified it as a partially self-incompatible cultivar. Self-incompatibility response was observed for 'Lastovka'. The positive response to crosspollination over self-pollination only in some experimental years classified 'Drobnica', 'Leccino', and 'Oblica' as partially self-incompatible. Results obtained from this study indicated that pollination efficiency is strictly combination-specific. The Italian cultivar, Leccino, was a successful pollen acceptor and pollenizer of most Croatian cultivars. Reciprocal high success in cross-pollination was recorded for 'Levantinka' and 'Oblica'. In the Mravince orchard, 'Lastovka', 'Leccino', and 'Oblica' were efficient pollenizers of 'Levantinka' where the simultaneous flowering period was in accordance with their crosscompatibility. 'Levantinka' was a good pollenizer for 'Lastovka' in the Mravince orchard, and both cultivars entered into the flowering period earlier than other studied cultivars, which was not the case in the other two orchards. The variations in flowering timing among orchards were a consequence of differences in environmental conditions. According to the high fruit sets recorded in 'Oblica' after pollination with 'Leccino' or 'Levantinka', an increase in tree productivity of the acceptor cultivar is expected in the presence of selected pollenizers in all olive-growing regions.
\end{abstract}

Olive trees are wind-pollinated and partially self-incompatible (Androulakis and Loupassaki, 1990; Cuevas et al., 2001; Lavee and Datt, 1978; Lavee et al., 2002), which is probably the result of the gametophytic system of self-incompatibility (Cuevas and Polito, 1997). For flower production during the spring, olive trees require chilling temperatures during the winter and an ample accumulation of heat units during the growing season (Orlandi et al., 2005).

Olive yield depends on the level of selfcompatibility and reproductive effectiveness of pollen sources (pollenizers) planted in the orchard. Pollination success often varies among years and causes a reduction in fruit set (Griggs et al., 1975; Quero et al., 2002). Orchard productivity depends on the combination of planted cultivars. Simultaneous flowering periods enable cross-pollination, fertilization, and fruit set of different cultivars if the recipients and pollenizers are compatible (Lavee et al., 2002). The knowledge of self-compatibility and cross-compatibility relationships of olives is important for pollination designs. These designs aim to improve production even in the case of self-compatible cultivars because the increase in fruit set under crossfertilization conditions has been extensively described (Cuevas et al., 2001; FernándezEscobar and Gómez-Valledor, 1985; Lavee et al., 2002).

A number of economically valuable olive cultivars have been introduced in Croatia during the last 30 years, and they have changed the design of orchards and pollination requirements. The Italian cultivars, Leccino and Pendolino, are the most common in newly planted Croatian orchards and are also present in the United States where high-quality Italian olives are grown for olive oil production (Vossen, 2007). The introduction of 'Leccino' occurred because of demands for improvement of Croatian olive oil production, and it was followed by introduction of 'Pendolino' because of the cross-pollination requirements. To date, there has been no systematic study of their pollination compatibility with traditional Croatian cultivars.

The Oblica cultivar is the most widespread olive cultivar in Croatia and is used for oil and table olive production. 'Oblica' usually grows in old, monovarietal olive groves and gives low yields. In newly established orchards where other cultivars are also present, however, the fruit set and yields of the 'Oblica' are usually increased (Selak, 2007). In Spain, Pinillos and Cuevas (2009) found that cultivars from neighboring plantations placed between $250 \mathrm{~m}$ and $500 \mathrm{~m}$ away from monovarietal 'Picual' orchards act as unsuspected pollenizers and increase the yield of selfincompatible cultivar. Moreover, low yields of cultivars in monovarietal olive groves may be enhanced by replanting or grafting trees with compatible cultivars (Lavee and Datt, 1978) or by mechanical application of compatible pollen (Sibbett et al., 1992). Other valuable cultivars in the Croatian olive oil industry are Drobnica, Lastovka, and Levantinka.

Information about the most successful, cross-compatible cultivar combinations in Croatia is poor or contradictory, especially given the increase in foreign cultivar introductions. A clear definition of the most successful, crosscompatible cultivar combinations with simultaneous flowering periods should improve fruit set and productivity. Therefore, the objective of this study was to analyze reproductive behavior of the most important Croatian cultivars, including Drobnica, Lastovka, Levantinka, and Oblica, and the most common Italian cultivars in newly planted orchards. Responses to crosspollination treatments of cultivars were compared with those after self-pollination to elucidate compatibility relationships within and among cultivars.

\section{Materials and Methods}

Experimental orchards. The experiments were conducted in three olive groves (Table 1) during three flowering seasons (2004, 2005, and 2006). Two orchards were located on the coastal part of Croatia (orchard in Kastela and orchard in Mravince), and the third orchard was located on the island of Brac. 
Breeding, Cultivars, Rootstocks, and Germplasm Resources

Table 1. Basic information about experimental orchards in the study.

\begin{tabular}{|c|c|c|c|}
\hline Orchard & Kastela & Mravince & Brac \\
\hline Location & Long. $43^{\circ} 33^{\prime} 26^{\prime \prime} \mathrm{N}$, lat. $16^{\circ} 21^{\prime} 8^{\prime \prime} \mathrm{E}$ & Long. $43^{\circ} 31^{\prime} 42^{\prime \prime} \mathrm{N}$, lat. $16^{\circ} 31^{\prime} 3^{\prime \prime} \mathrm{E}$ & Long. $43^{\circ} 15^{\prime} 43^{\prime \prime} \mathrm{N}$, lat. $16^{\circ} 38^{\prime} 58^{\prime \prime} \mathrm{E}$ \\
\hline Altitude & $30 \mathrm{~m}$ & $80 \mathrm{~m}$ & $40 \mathrm{~m}$ \\
\hline Orchard age & 30 years & 20 years & 20 years \\
\hline Studied cultivars & $\begin{array}{l}\text { Drobnica, Lastovka, Levantinka, Oblica, } \\
\text { Leccino, Pendolino }\end{array}$ & $\begin{array}{l}\text { Lastovka, Levantinka, Oblica, } \\
\text { Leccino, Pendolino }\end{array}$ & Lastovka, Levantinka, Oblica, Leccino \\
\hline Experimental years & $2004,2005,2006$ & 2005,2006 & 2006 \\
\hline
\end{tabular}

The experimental orchards differed by cultivar structure. The autochthonous cultivars, including Drobnica, Lastovka, Levantinka, and Oblica, and the Italian cultivars, Leccino and Pendolino, were included in the study. The orchard in Kastela was an experimental autochthonous olive cultivar collection of the Institute for Adriatic Crops, and it was only $50 \mathrm{~m}$ from the collection of introduced cultivars. A mixed autochthonous/introduced cultivar structure was present in the Mravince orchard, and the olive grove on the island of Brac contained only autochthonous cultivars. The agricultural management practices were similar in the three experimental orchards.

In each experimental year, at least four trees of each cultivar were selected for their uniform size and high level of flowering. The flowering period was assessed by visual examination of eight trees per cultivar according to Barranco et al. (1994). The average flowering date (AFD) is the number of days from $1 \mathrm{Jan}$. until the start of the flowering period. The AFD was calculated for each experimental year using flowering dates of all tested cultivars.

Meteorological data. Meteorological data were provided by the National Meteorological and Hydrological Service from their stations no further than $10 \mathrm{~km}$ from the experimental orchards (Table 2). The method proposed by Aron and Gat (1991) was used to estimate the number of chilling units (CU) using the daily maximal and minimal air temperatures. An hour of chilling is accumulated if the hourly air temperature is below $7.2{ }^{\circ} \mathrm{C}$. The chilling period was considered to start at the first day in fall when the mean daily air temperature dropped below $7.2{ }^{\circ} \mathrm{C}$ followed by subsequent days characterized by low (less than $7.2^{\circ} \mathrm{C}$ ) air temperatures and lasted until the end of March. The heat accumulation start dates were the first days after the calculations of CUs were stopped (early spring) and were calculated up to the start of flowering season. Heat units were expressed in growing degree-days (GDD), and

Received for publication 4 Aug. 2010. Accepted for publication 22 Nov. 2010.

The study was partially supported by the Croatian Ministry of Science, Education and Sports (grant no. 091-0910468-0166) and by the Croatian Ministry of Agriculture, Fisheries and Rural Development (grant no. V-16-7/04).

We acknowledge the contributions of Ana Vidak and thank her for valuable technical assistance, and we also thank Julián Cuevas, who reviewed an early draft of the manuscript.

${ }^{1}$ To whom reprint requests should be addressed; e-mail gabriela@krs.hr. one GDD unit represents $1^{\circ} \mathrm{C}$ above threshold $\left(12.5^{\circ} \mathrm{C}\right)$ temperature in $24 \mathrm{~h}$. Heat units were calculated according to Orlandi et al. (2005).

Pollination experiment. On each replicate tree, four branches with 20 inflorescences were chosen for each pollination treatment (self-pollination, free pollination, and crosspollination). Additional inflorescences were hand-thinned before bloom. The number of flowers within 20 inflorescences was recorded. According to Cuevas and Polito (1997), the shoots chosen for self-pollination and crosspollination were covered with a paper bag immediately before flower opening until loss of stigma receptivity. The shoots for free pollination were marked and exposed to wind pollination. The paper bags used for branch isolation were resistant to rain but enabled adequate gas exchange. Flowers within the bags were not emasculated to reflect field conditions.

Cross-pollination treatments were performed during the period of full bloom. The branches of pollen donor cultivars with opened flowers and dehiscent anthers were detached. Cross-pollination treatments were carried out by opening the bags, inserting the pollinator branches, and enclosing them in the bags. The bags were shaken daily to enhance pollination. Shoots chosen for self-pollination were enclosed until the end of anthesis. 'Drobnica', 'Lastovka', 'Leccino', 'Levantinka', and 'Oblica' were used as pollen acceptors and pollen donors (pollenizers), and 'Pendolino' was used as a pollenizer in two experimental olive groves (Kastela and Mravince).

The initial and final fruit set in response to the pollination treatments were assessed in the isolated shoots. The initial fruit set, expressed as the percentage of the number of developing fruits within the number of flowers counted in 20 inflorescences, was calculated $20 \mathrm{~d}$ after full bloom and before heavy fruit drop. The final fruit set, expressed as the percentage of the number of developed fruits within the number of flowers counted in 20 inflorescences, was calculated at $45 \mathrm{~d}$ to $60 \mathrm{~d}$ after full bloom when the abscission of young fruitlets was completed (adapted from Cuevas et al., 2001). The ISI was calculated by dividing the final fruit set under self-pollination by the fruit set under free pollination or cross-pollination for each experimental year and orchard as previously proposed (Cuevas et al., 2001; Zapata and Arroyo, 1978).

Data analysis. The data for the percentage of fruit set were arcsine transformed and then subjected to analysis of variance using proc GLM using SAS software (SAS Institute, Inc., Cary, NC). Mean separations were done by the least significant difference test at $P \leq 0.05$.

\section{Results and Discussion}

\section{Flowering timing and climatic conditions}

The differences in length and timing of flowering period are closely related to the climatic conditions between growing regions and experimental years even in the same region (Lavee et al., 2002). The climatic factors recorded in this study were summarized as the accumulated CU and GDD (Table 2). The date of reproductive budburst (Orlandi et al., 2004) and flowering time (Lavee et al., 2002) was delayed at locations with more accumulated CU. In our study, an influence of accumulated $\mathrm{CU}$ on flowering date was studied. The CU ranged between 1193.3 at $\mathrm{Brac}$ (2006) to 1511.9 at Kastela (2005), and no significant relation to AFD was found (data not shown). The heat accumulation, expressed as GDD, varied from 120 at Brac (May 2006) to 155 at Mravince (May 2006). According to these data, the olive trees in each experimental orchard were exposed to a sufficient period of chilling temperatures (Hartmann and Porlingis, 1957) and subsequent heat amounts (Alcalá and Barranco, 1992) to produce flowers. High temperatures shorten the flowering period (Barranco et al., 1994). An influence of high temperature (greater than $31^{\circ} \mathrm{C}$ ) was noticed for the cultivars in Kastela during the 2005 flowering season, and a prolonged flowering period was associated with lower temperatures in May 2004 (Table 2; Fig. 1).

\section{Flowering schedule of studied cultivars}

Simultaneous flowering is important in achieving a high fruit set after cross-pollination (Cuevas et al., 2009). Researchers have emphasized the importance of selecting pollenizer cultivars with flowering periods that are consistently simultaneous with a main cultivar, especially in cultivars with a short effective pollination period. The flowering periods of most of the studied cultivars overlapped to some degree in each experimental year and orchard (Fig. 1). In Kastela, the flowering periods of the studied cultivars lasted from 24 May (start of flowering recorded in 'Lastovka') to 5 June (end of flowering recorded in 'Levantinka') in 2004. In 2005, the flowering periods of all cultivars were shortened. The flowering of studied cultivars started $1 \mathrm{~d}$ earlier ('Pendolino') and finished $4 \mathrm{~d}$ earlier ('Levantinka') than in 2004. The flowering periods during 2005 and 2006 in Kastela were similar, which was probably the result of comparable temperature conditions (Fig. 1; Table 2). In the 3 experimental years, 'Lastovka' and 'Pendolino' started flowering before other tested cultivars in Kastela, and the full bloom did not occur at the same 
Table 2. Monthly average maximal/minimal air temperatures $\left({ }^{\circ} \mathrm{C}\right)$ from October of previous year until May in flowering season, accumulated chilling units $(\mathrm{CU})$, growing degree-days (GDD), and average flowering date (AFD) in the experimental orchards at Kastela, Mravince, and Brac during 2004, 2005 , and 2006.

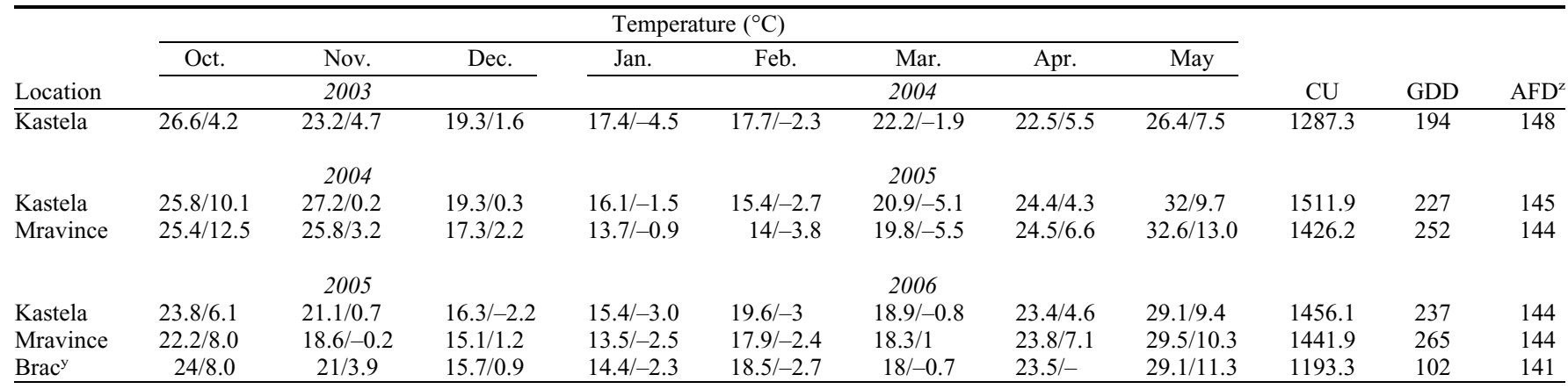

${ }^{\mathrm{z}} \mathrm{AFD}=$ number of days from 1 Jan. until average start of flowering period of observed cultivars.

${ }^{\mathrm{y}} \mathrm{GDD}$ for Brac location was calculated only from air temperature data recorded during May.

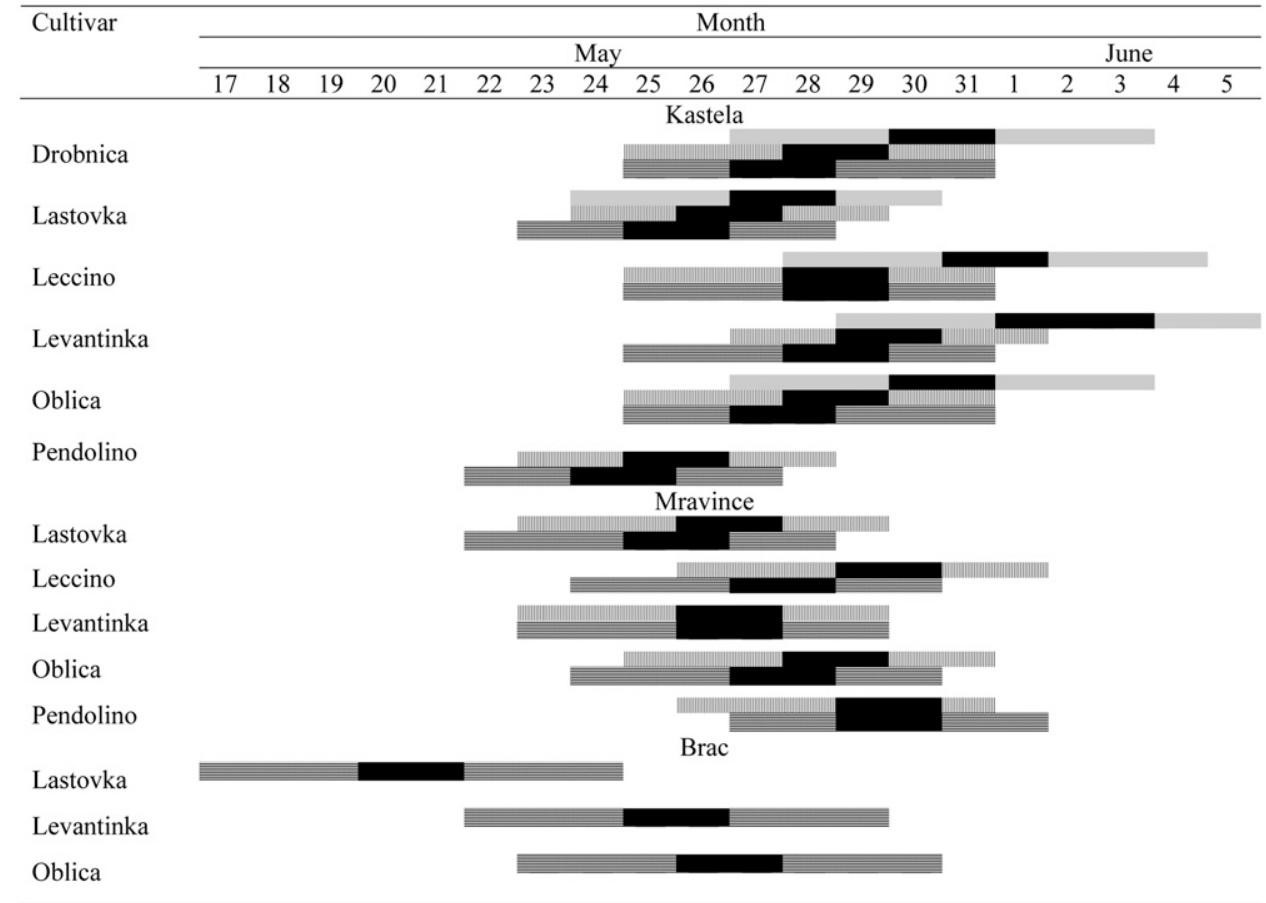

Fig. 1. Flowering period of studied cultivars during 3 years in the costal (Kastela and Mravince) and island (Brac) part of Croatia; gray-filled area $=2004$; vertical lines $=2005$; horizontal lines $=2006$; black-filled area denotes full bloom period.

time with other cultivars, which reduced the possibility for abundant pollen exchange. The latest observed flowering periods were those of 'Levantinka' and 'Leccino'. Full simultaneous flowering and full bloom periods were recorded for 'Drobnica', 'Leccino', and 'Oblica' in all experimental years. The flowering timing and schedule of tested cultivars recorded in Mravince differed from those in the collection orchard in Kastela (Fig. 1). 'Levantinka' and 'Lastovka' started flowering simultaneously and earlier (both cultivars on 23 May 2005; 'Lastovka' on 22 May 2006; and 'Levantinka' on 23 May 2006) than other studied cultivars. Simultaneous flowering and full bloom were recorded for 'Leccino' and 'Oblica' in Kastela. The latest flowering date at Mravince was recorded for 'Pendolino', although it initiated flowering in Kastela. 'Levantinka' and 'Oblica' started simultaneously flowering and full bloom in Brac. 'Lastovka' had the earliest flowering in all experimental years and orchards.

\section{Pollination experiments}

Initial fruit set. Differences between treatments (self-pollination, cross-pollination, and free pollination) were investigated on the level of initial and final fruit set to determine if the relations that exist at the early response (initial fruit set) correspond to those that follow (final fruit set). When compared with self-pollination, the increase of fruit set in some olive cultivars after different cross-pollination or free pollination treatments was apparent at the time of initial fruit set (Tables 3, 4, and 5). However, the degree of increase was dependent on cultivar, year, and location. In 'Leccino', free pollination enhanced initial fruit set when compared with self-pollination during 2 experimental years in Kastela but only during 1 year in Mravince (2006). The apparent influence of free pollination over self-pollination was also found for 'Levantinka' in all experimental years and orchards. Furthermore, a positive response to free pollination was found at certain orchards and years for 'Drobnica' (Kastela, 2006), 'Lastovka' (Kastela, 2005 and 2006; Mravince, 2006), and 'Oblica' (Kastela, 2004; Mravince, 2006).

A higher or equalized initial fruit set after self-pollination when compared with crosspollination or free pollination treatment was found for 'Drobnica' (Kastela, 2004; Mravince, 2005), 'Leccino', and 'Oblica' (Mravnice, 2005). In these cultivars, parthenocarpic shotberries were abundantly produced after selfpollination treatment, which is a situation that has been previously reported (FernándezEscobar and Gómez-Valledor, 1985; Sibbett et al., 1992). Rallo et al. (1990) reported delayed fruit abscission in Frantoio, Manzanilla, and Moraiolo cultivars after self-pollination when 
Table 3. Initial (IFS) and final (FFS) fruit set (fruit number/number of flowers within 20 inflorescences) in 'Drobnica', 'Lastovka', 'Leccino', 'Levantinka', and 'Oblica' after self-pollination, free pollination (FP), and cross-pollination in Kastela orchard in 2004, 2005, and 2006.

\begin{tabular}{|c|c|c|c|c|c|c|c|c|c|c|}
\hline \multirow{4}{*}{ Pollenizer } & \multicolumn{10}{|c|}{ Cultivar } \\
\hline & \multicolumn{2}{|c|}{ Drobnica } & \multicolumn{2}{|c|}{ Lastovka } & \multicolumn{2}{|c|}{ Leccino } & \multicolumn{2}{|c|}{ Levantinka } & \multicolumn{2}{|c|}{ Oblica } \\
\hline & IFS & FFS & IFS & FFS & IFS & FFS & IFS & FFS & IFS & FFS \\
\hline & \multicolumn{10}{|c|}{ Fruit set (\%) } \\
\hline$\overline{x \text { Drobnica }}$ & $27.48 \mathrm{a}^{\mathrm{z}}$ & $1.00 \mathrm{c}$ & & - & $14.53 \mathrm{a}$ & $5.62 \mathrm{ab}$ & $3.73 \mathrm{bc}$ & $2.98 \mathrm{~b}$ & $6.34 \mathrm{a}$ & $1.12 \mathrm{bc}$ \\
\hline$\times$ Lastovka & - & - & $0.82 \mathrm{~b}$ & $0.41 \mathrm{~b}$ & - & - & - & - & $2.97 \mathrm{~b}$ & $1.42 \mathrm{~b}$ \\
\hline$\times$ Leccino & $13.44 \mathrm{~b}$ & $4.48 \mathrm{ab}$ & - & - & $1.49 \mathrm{c}$ & $1.05 \mathrm{c}$ & $6.75 \mathrm{~b}$ & $2.48 \mathrm{bc}$ & $3.41 \mathrm{~b}$ & $0.82 \mathrm{~cd}$ \\
\hline \multirow[t]{2}{*}{ FP } & $8.73 \mathrm{~b}$ & $5.67 \mathrm{a}$ & $8.73 \mathrm{a}$ & $4.80 \mathrm{a}$ & $13.98 \mathrm{a}$ & $8.06 \mathrm{a}$ & $12.33 \mathrm{a}$ & $6.16 \mathrm{a}$ & $6.71 \mathrm{a}$ & $2.81 \mathrm{a}$ \\
\hline & \multicolumn{10}{|c|}{2005} \\
\hline$\times$ Drobnica & - & - & - & - & - & $8.45 \mathrm{a}$ & - & - & - & $3.99 \mathrm{ab}$ \\
\hline$\times$ Lastovka & - & - & - & $0.18 \mathrm{~b}$ & - & $3.27 \mathrm{~b}$ & - & - & - & - \\
\hline$\times$ Leccino & - & - & - & - & - & $0.96 \mathrm{c}$ & - & - & - & $6.45 \mathrm{ab}$ \\
\hline$\times$ Levantinka & - & - & - & $0.80 \mathrm{~b}$ & - & - & - & - & - & $5.94 \mathrm{a}$ \\
\hline FP & \multicolumn{10}{|c|}{2006} \\
\hline$\times$ Drobnica & $1.49 \mathrm{~d}$ & $0.87 \mathrm{c}$ & - & — & $17.66 \mathrm{~b}$ & $3.83 \mathrm{~b}$ & $6.21 \mathrm{~b}$ & $1.31 \mathrm{~b}$ & $1.40 \mathrm{~b}$ & $0.62 \mathrm{ab}$ \\
\hline$\times$ Lastovka & $9.37 \mathrm{a}$ & $4.38 \mathrm{a}$ & $3.89 \mathrm{~b}$ & $0.19 \mathrm{~b}$ & $6.98 \mathrm{c}$ & $4.17 \mathrm{~b}$ & $6.04 \mathrm{~b}$ & $2.23 \mathrm{~b}$ & $0.82 \mathrm{~b}$ & $0.33 \mathrm{~b}$ \\
\hline$\times$ Leccino & $5.92 \mathrm{bc}$ & $1.80 \mathrm{~b}$ & - & - & $0.60 \mathrm{~d}$ & $0.51 \mathrm{c}$ & $5.73 \mathrm{~b}$ & $1.98 \mathrm{~b}$ & $0.77 \mathrm{~b}$ & $0.61 \mathrm{ab}$ \\
\hline$\times$ Levantinka & $6.91 \mathrm{ab}$ & $3.13 \mathrm{ab}$ & - & - & $23.74 \mathrm{ab}$ & $8.43 \mathrm{a}$ & $5.80 \mathrm{~b}$ & $1.76 \mathrm{~b}$ & $1.60 \mathrm{~b}$ & $0.72 \mathrm{ab}$ \\
\hline$\times$ Oblica & $5.27 \mathrm{bc}$ & $2.77 \mathrm{ab}$ & - & - & $10.24 \mathrm{c}$ & $5.46 \mathrm{~b}$ & $10.96 \mathrm{a}$ & $3.55 \mathrm{a}$ & $3.52 \mathrm{ab}$ & $0.21 \mathrm{~b}$ \\
\hline FP & $3.65 \mathrm{c}$ & $2.84 \mathrm{~b}$ & $12.07 \mathrm{a}$ & $5.42 \mathrm{a}$ & $30.53 \mathrm{a}$ & $9.39 \mathrm{a}$ & $14.08 \mathrm{a}$ & $4.90 \mathrm{a}$ & $4.11 \mathrm{a}$ & $1.05 \mathrm{a}$ \\
\hline
\end{tabular}

${ }^{\mathrm{z}}$ Different letters within column for each year indicate significant differences at $P \leq 0.05$ by least significant difference test.

Table 4. Initial (IFS) and final (FFS) fruit set (fruit number/number of flowers within 20 inflorescences) in 'Lastovka', 'Leccino', 'Levantinka', and 'Oblica' after self-pollination, free pollination (FP), and cross-pollination during two flowering seasons in Mravince orchard.

\begin{tabular}{|c|c|c|c|c|c|c|c|c|}
\hline \multirow{3}{*}{ Pollenizer } & \multicolumn{8}{|c|}{ Cultivar } \\
\hline & \multicolumn{2}{|c|}{ Lastovka } & \multicolumn{2}{|c|}{ Leccino } & \multicolumn{2}{|c|}{ Levantinka } & \multicolumn{2}{|c|}{ Oblica } \\
\hline & \multicolumn{8}{|c|}{ Fruit set $(\%)$} \\
\hline$\times$ Drobnica & $36.46 \mathrm{bc}^{2}$ & $4.73 \mathrm{~b}$ & $27.03 \mathrm{ab}$ & $5.97 \mathrm{a}$ & $3.29 \mathrm{~cd}$ & $2.48 \mathrm{a}$ & $12.34 \mathrm{ab}$ & $3.41 \mathrm{ab}$ \\
\hline$\times$ Lastovka & $49.06 \mathrm{a}$ & $0.95 \mathrm{~d}$ & $21.71 \mathrm{bc}$ & $5.07 \mathrm{a}$ & $11.78 \mathrm{a}$ & $5.73 \mathrm{a}$ & $11.51 \mathrm{~b}$ & $3.96 \mathrm{a}$ \\
\hline$\times$ Leccino & $33.22 \mathrm{bc}$ & $4.67 \mathrm{~b}$ & $51.37 \mathrm{a}$ & $1.78 \mathrm{~b}$ & $8.43 \mathrm{abc}$ & $6.03 \mathrm{a}$ & $9.33 \mathrm{~b}$ & $3.34 \mathrm{ab}$ \\
\hline \multirow[t]{2}{*}{ FP } & $14.79 \mathrm{~d}$ & $3.09 \mathrm{bc}$ & $5.34 \mathrm{c}$ & $2.43 \mathrm{~b}$ & $9.79 \mathrm{ab}$ & $5.34 \mathrm{a}$ & $6.31 \mathrm{c}$ & $2.86 \mathrm{ab}$ \\
\hline & \multicolumn{8}{|c|}{2006} \\
\hline$\times$ Drobnica & $9.71 \mathrm{ab}$ & $2.24 \mathrm{bc}$ & $19.58 \mathrm{~b}$ & $6.38 \mathrm{a}$ & $14.60 \mathrm{ab}$ & $3.22 \mathrm{~cd}$ & $4.54 \mathrm{~b}$ & $2.15 \mathrm{~b}$ \\
\hline$\times$ Lastovka & $5.91 \mathrm{c}$ & $0.40 \mathrm{~d}$ & $10.70 \mathrm{~cd}$ & $6.27 \mathrm{a}$ & $12.16 \mathrm{~b}$ & $4.47 \mathrm{abc}$ & $2.82 \mathrm{~b}$ & $1.44 \mathrm{c}$ \\
\hline$\times$ Leccino & $6.77 \mathrm{bc}$ & $1.51 \mathrm{c}$ & $1.64 \mathrm{e}$ & $1.04 \mathrm{~b}$ & $12.99 \mathrm{ab}$ & $4.40 \mathrm{abc}$ & $2.74 \mathrm{~b}$ & $1.65 \mathrm{bc}$ \\
\hline
\end{tabular}

${ }^{\mathrm{Z}}$ Different letters within column for each year indicate significant differences at $P \leq 0.05$ by least significant difference test.

Table 5. Initial (IFS) and final (FFS) fruit set (fruit number/number of flowers within 20 inflorescences) in 'Lastovka', 'Levantinka', and 'Oblica' after self-pollination, free pollination (FP), and crosspollination during 2006 flowering season in Brac orchard.

\begin{tabular}{|c|c|c|c|c|c|c|}
\hline \multirow[b]{4}{*}{ Pollenizer } & \multicolumn{6}{|c|}{ Cultivar } \\
\hline & \multicolumn{2}{|c|}{ Lastovka } & \multicolumn{2}{|c|}{ Levantinka } & \multicolumn{2}{|c|}{ Oblica } \\
\hline & IFS & FFS & IFS & FFS & IFS & FFS \\
\hline & \multicolumn{6}{|c|}{ Fruit set $(\%)$} \\
\hline$\overline{\times \text { Lastovka }}$ & $4.04 \mathrm{a}^{\mathrm{z}}$ & $0.29 \mathrm{~b}$ & $2.21 \mathrm{~b}$ & $0.62 \mathrm{~b}$ & $3.50 \mathrm{ab}$ & $0.45 \mathrm{~b}$ \\
\hline$\times$ Levantinka & & - & $2.46 \mathrm{~b}$ & $0.59 \mathrm{~b}$ & $9.03 \mathrm{a}$ & $1.87 \mathrm{a}$ \\
\hline$\times$ Oblica & & - & $3.14 \mathrm{~b}$ & $1.00 \mathrm{~b}$ & $1.44 \mathrm{~b}$ & $0.13 \mathrm{~b}$ \\
\hline FP & $4.57 \mathrm{a}$ & $3.52 \mathrm{a}$ & $13.85 \mathrm{a}$ & $2.84 \mathrm{a}$ & $2.74 \mathrm{ab}$ & $1.88 \mathrm{a}$ \\
\hline
\end{tabular}

${ }^{\mathrm{z}}$ Different letters within column for each year indicate significant differences at $P \leq 0.05$ by least significant difference test. compared with cross-pollination, which can also explain higher initial fruit set after selfpollination.

Final fruit set. During the 3 experimental years, free pollination and most of the crosspollination treatments conducted in Kastela improved final fruit set when compared with self-pollination (Table 3). The exception was found in 'Levantinka' in which no significant differences were found between the final fruit set in self-pollination and most of the crosspollination treatments in 2006. Increased final fruit set and yield after free pollination and 
cross-pollination when compared with selfpollination have also been widely reported for different olive cultivars in other regions (Ateyyeh et al., 2000; Cuevas et al., 2001; Cuevas and Polito, 1997; Lavee et al., 2002). In Mravince, the positive response of final fruit set to cross-pollination was more consistent than in Kastela (Table 4). Increased final fruit set under cross-pollination conditions when compared with self-pollination was recorded for all cultivars and years except for 'Levantinka'. The final fruit set after self-pollination in 'Levantinka' was as successful as each crosspollination combination in 2005 or as successful as cross-pollination treatments with 'Drobnica' and 'Pendolino' in 2006. Free pollination in each cultivar improved final fruit set when compared with self-pollination treatment in Brac, although no such clear response over self-pollination was noticed in 'Levantinka' and 'Oblica' for cross-pollination treatments (Table 5). The final fruit set in 'Oblica' was significantly increased by application of the pollen from 'Levantinka' (1.87\%) when compared with the fruit set after pollination with its own pollen $(0.13 \%)$. The higher final fruit set in the free pollination treatment when compared with cross-pollination was recorded for several cultivars. The higher final fruit set was evident in 'Levantinka' in all locations and years with the exception of the final fruit set in Mravince during 2005. The increased fruit set under free pollination was probably the result of more favorable environmental conditions in opened branches than in those in enclosed bags. Increased temperature in enclosed branches may reduce fruit set. Therefore, the comparison of cross-pollination and free pollination should be considered with some reservations because the conditions for fruit set under enclosed and open conditions may be different. Finally, initial and final fruit set results only partially corresponded because a diverse fruit drop dynamic was noticed in different pollination treatments.

Reproductive compatibility. A significant variability in fruit set was found regarding the response of any receptor cultivar to pollination with a specific pollenizer. In some experimental years, however, pollenizer/acceptor cultivar combinations were particularly efficient in inducing final fruit set ('Levantinka'/'Leccino' and 'Oblica'/'Levantinka' in Kastela during 2006; 'Levantinka'/'Lastovka' in Mravince during 2 years), and a lower fruit set was found in all other cross combinations. Lavee et al. (2002) have divided the pollenizers into four efficiency groups based on the level of fruit set in relation to self-pollination. According to proposed methodology, no pollenizer from the group with highest efficiency (51-fold to 100 -fold increase in fruit after cross-pollination) was found in this study. Pollenizers with high efficiency (11-fold to 50-fold increase) were considered to be 'Levantinka' and 'Oblica' during 2006 in Kastela when Leccino was the pollen acceptor cultivar. 'Levantinka' was a highly efficient pollenizer for 'Oblica' in Brac, and such efficiency for the Oblica cultivar was recorded for all pollenizers in Mravince (2006). Efficient pollen donors for 'Oblica' in Kastela, which were donors that induced a significant increase in final fruit set after cross-pollination when compared with self-pollination, were 'Levantinka' (sixfold increase in 2004, 3.7fold increase in 2005, and 3.5-fold increase in 2006), 'Leccino' (2.7-fold increase in 2004, fourfold increase in 2005, and threefold increase in 2006), and 'Drobnica' (3.7-fold increase in 2004, 2.4-fold increase in 2005, and threefold increase in 2006). Furthermore, 'Levantinka' was the most efficient pollenizer for the 'Lastovka' in Mravince during both experimental years.

\section{Index of self-incompatibility}

The ISI, a concept introduced by Lloyd (1965), has been shown to be useful for assessing the degree of self-incompatibility in plant species. Olive cultivars showing ISI values consistently lower than 0.1 are classified as self-incompatible (Androulakis and Loupassaki, 1990). Cuevas and Polito (1997) proposed that the Manzanillo cultivar is selfincompatible, although the ISI of 'Manzanillo' ranged from 0.22 to 0.24 . Cultivars that have been reported as self-incompatible in some studies such as 'Manzanilla de Sevilla' (Cuevas and Polito, 1997) are found in other studies to be partly self-compatible (Wu et al., 2002) or self-compatible (Fernández-Escobar and Rallo, 1981). The inconsistent results obtained in various pollination experiments may be partially the result of the differences in environmental conditions among sites. Variable selffertility behavior depending on orchard and season was also found for cultivars in this study. The ISI calculated for 'Levantinka' in all experimental orchards ranged as follows: from 0.24 to 1.34 in Kastela, from 0.36 to 0.89 in Mravince, and from 0.21 to 0.95 in Brac. The quoted ISI values classified 'Levantinka' as a partially self-incompatible cultivar. Low ISI under most of the experimental conditions was noticed for 'Lastovka' in which the selfincompatibility response was correlated with low self-pollination efficiency when compared with cross-pollination and free pollination treatments. Furthermore, ISI considerably changed among sites and years in 'Drobnica', 'Leccino', and 'Oblica'. These cultivars were classified as partially self-incompatible because a positive response to cross-pollination was noticed only in particular years for 'Leccino' and 'Oblica' and in 2 years for 'Drobnica'.

\section{Pollenizer efficiency}

Based on increased fruit set under crosspollination when compared with self-pollination, pairs of cultivars have been proposed to be cross-compatible. The best pollenizer for each pollen acceptor cultivar was selected according to a high final fruit set after crosspollination during at least two flowering seasons. Cross-incompatibility among tested cultivars was not found. Simultaneous flowering periods among tested cultivars was related to their cross-compatibility. Divergence in the flowering period of 'Lastovka' with all tested cultivars in Kastela caused an absence of most cross-pollination treatments; however, 'Levantinka' behaved as a good pollen- izer for 'Lastovka' in Mravince. 'Levantinka' and 'Drobnica' responded positively to cross-pollination with 'Oblica', and the cross-compatibility after pollination between 'Levantinka' and 'Oblica' was bidirectional. The Italian cultivar, Leccino, was an efficient pollen donor or acceptor for most Croatian cultivars, although low germinability of its pollen was found in vitro (data not shown). 'Pendolino' successfully pollinated 'Leccino' and 'Levantinka' in Mravince. In Kastela, 'Pendolino' was used as a pollenizer in only 1 year, which was insufficient to confirm its compatibility with tested cultivars.

In conclusion, the variable response to cross-pollination that was noticed in this study corresponds to other studies (Cuevas et al., 2001; Griggs et al., 1975; Lavee et al., 2002). The results obtained in this study indicate that pollination efficiency is strictly combinationspecific, which has been suggested by other researchers (Cuevas et al., 2001; Lavee et al., 2002; Moutier, 2002). The most important olive oil cultivar, Oblica, is partially selfincompatible and cross-compatible with 'Leccino', 'Levantinka', and other tested cultivars in Croatia. These observations suggest that replanting or grafting a number of trees with 'Leccino' or 'Levantinka' may enhance the tree productivity in 'Oblica' in monocultivar orchards. To achieve high yields, new areas of olive production should incorporate crosscompatible cultivars.

\section{Literature Cited}

Alcalá, A.R. and D. Barranco. 1992. Prediction of flowering time in olive for the Cordoba olive collection. HortScience 27:1205-1207.

Androulakis, I.I. and M.H. Loupassaki. 1990. Studies on the self-fertility of some olive cultivars in the area of Crete. Acta Hort. 286:159-162.

Aron, R. and Z. Gat. 1991. Estimating chilling duration from daily temperature extremes and elevation in Israel. Clim. Res. 1:125-132.

Ateyyeh, A.F., R. Stosser, and M. Qrunfleh. 2000. Reproductive biology of the olive (Olea europaea L.) cultivar 'Nabali Baladi'. J. Appl. Bot. 74:255-270.

Barranco, D., G. Milona, and L. Rallo. 1994. Épocas de floración de cultivares de olivo en Córdoba. Investigación Agraria. Producctión y Protección Vegetales 9:213-220.

Cuevas, J., A.J. Díaz-Hermoso, D. Galián, J.J. Hueso, V. Pinillos, M. Prieto, D. Sola, and V.S. Polito. 2001. Response to cross pollination and choice of pollinators for the olive cultivars (Olea europaea L.) 'Manzanilla de Sevilla', 'Hojiblanca', and 'Picual'. Olivae 85:26-32.

Cuevas, J., V. Pinillos, and V.S. Polito. 2009. Effective pollination period for 'Manzanillo' and 'Picual' olive trees. J. Hort. Sci. Biotechnol. 84:370-374.

Cuevas, J. and V.S. Polito. 1997. Compatibility relationships in 'Manzanillo' olive. HortScience 32:1056-1058.

Fernández-Escobar, R. and G. Gómez-Valledor. 1985. Cross-pollination in 'Gordal Sevillana' olives. HortScience 20:191-192.

Fernández-Escobar, R. and L. Rallo. 1981. Influencia de la polinización cruzada en el cuajado de frutos de cultivares de olivo (Olea europaea L.). ITEA 45:51-58.

Griggs, W.H., H.T. Hartmann, M.V. Bradley, B.T. Iwakiri, and J.E. Whisler. 1975. Olive 
pollination in California. California Agr. Expt. Sta. Bul. 869:1-50.

Hartmann, H.T. and I.C. Porlingis. 1957. Effect of different amounts of winter chilling on fruitfulness of several olive varieties. Bot. Gaz. 119:102-104.

Lavee, S. and Z. Datt. 1978. The necessity of crosspollination for fruit set of 'Manzanillo' olives. J. Hort. Sci. 53:261-266.

Lavee, S., J. Taryan, J. Levin, and A. Haskal. 2002. The significance of cross-pollination for various olive cultivars under irrigated intensive growing conditions. Olivae 91:25-36.

Lloyd, D.G. 1965. Evolution of self-incompatibility and racial differentiation in Leavenworthia (Cruciferae). Contrib. Grey Herb. 195:3-134.

Moutier, N. 2002. Self-fertility and inter-compatibilities of sixteen olive varieties. Acta Hort. 586:209-212.
Orlandi, F., H. García-Mozo, L. Vazquez Ezquerra, B. Romano, E. Domínguez, C. Galán, and M. Fornaciari. 2004. Phenological olive chilling requirements in Umbria (Italy) and Andalusia (Spain). Plant Biosyst. 138:111-116.

Orlandi, F., L. Ruga, B. Romano, and M. Fornaciari 2005. Olive flowering as an indicator of local climatic changes. Theor. Appl. Climatol. 81: 169-176.

Pinillos, V. and J. Cuevas. 2009. Open-pollination provides sufficient levels of cross-pollen in Spanish monovarietal olive orchards. HortScience 44:499-502.

Rallo, L., J. Cuevas, and H. Rapoport. 1990. Fruit set pattern in self- and open-pollinated olive cultivars. Acta Hort. 286:219-222.

Quero, A., V. Pinillos, and J. Cuevas. 2002. Reduced ovule longevity increases cross-pollination response in olive. Acta Hort. 586:469-472.
Selak, G.V. 2007. Reproductive compatibility of important olive (Olea europaea L.) cultivars in Dalmatia region. MSc Thesis, Zagreb Univ., Zagreb, Croatia.

Sibbett, G., M. Freeman, L. Ferguson, and V. Polito. 1992. Effect of topically applied 'Sevillano' pollen on normal seeded and parthenocarpic 'shotberry' and fruit set of 'Manzanillo' olive. HortTechnology 2:228-230.

Vossen, P. 2007. Olive oil: History, production, and characteristics of the world's classic oils. HortScience 42:1093-1100.

Wu, S., G. Collins, and M. Sedgley. 2002. Sexual compatibility within and between olive cultivars. J. Hort. Sci. 77:665-673.

Zapata, T.R. and M.T.K. Arroyo. 1978. Plant reproductive ecology of a secondary deciduous tropical forest in Venezuela. Biotropica 10 221-230. 